\title{
Social Media Tools for Informal Language Learning: A Comprehensive Theoretical Framework
}

\author{
Che Wan Ida Rahimah Bt. Che Wan Ibrahim ${ }^{1}$ \\ ${ }^{1}$ Centre for Liberal and Fundamental Education, Universiti Malaysia Terengganu, Terengganu, Malaysia \\ Correspondence: Che Wan Ida Rahimah Bt. Che Wan Ibrahim. E-mail: idaray@umt.edu.my
}

Received: October 2, 2017

Accepted: March 3, 2018

Online Published: March 20, 2018

doi:10.5539/ass.v14n4p46

URL: https://doi.org/10.5539/ass.v14n4p46

\begin{abstract}
This article offers a conceptual framework for social media applications that provides efficient support for a daily informal language learning experience. It proposes the multiple lenses of sociocultural theories as conceptual and interpretive tools, to capture the complexity and the fine-grained types of activities of these learner-users' sociocultural experiences in informal English as a Second Language learning via social media at residential college of Malaysian universities. These theories focus not only on the development of individual language learner's cognitive development but also on the overall development of learners. The proposed framework provides forward technology support for the successful design of the future language informal learning.
\end{abstract}

Keywords: informal learning, English as a second language learning, social media tools, activity theory

\section{Introduction}

In line with the Malaysian Government's Vision 2020 for education transformation, skills in technology using English have been foregrounded across Malaysian education institutions (Wan, 2013). Particularly with the availability and range of social media resources, and the dominance of English as global language, Malaysia aspires to meet international demands in order to be at the forefront of a globalisation.

At heart, residential college is increasingly recognised as an authentic environment for informal learning of English as a Second Language that empowers university students to discover knowledge and participate more effectively in daily life. Informal learning takes place through the activities that initiated by learners (through self-guidance) in informal settings that result in the development of their English knowledge and skills (Wan, 2013). Indeed, learners may empower their daily language learning through the use of a variety of social media widgets, such as Facebook, YouTube, Wikis, and blogs (Wan, Prain, \& Collet, 2014). In the next section, the writer proposes on the theoretical appropriateness for Malaysian learners' practical application of emerging social media tools in their informal English as a second language learning, using activity theory frameworks.

\subsection{Mediation in Sociocultural Theory}

Activity theory studies of learning involve analyses of artefact-mediated activity, situated in cultural and historical contexts, with an emphasis on social mediation processes (Kaptelinin \& Nardi, 2006; Lantolf \& Thorne, 2006). Supporting this, the principle of mediation provides a lens for examining participants' ESL learning in corridors, cafeterias and beyond the classroom by suggesting that learner-users are active agents strategically appropriating social cultural tools of social media in social networking. Vygotsky's (1978) activity theory represents the basic relationship between a subject (individual or group) and a cultural artefact (a physical or cognitive tool) in order to transform an object (a goal, objective, purpose or problem) (Wan, 2013). However, Vygotsky's (1978) basic representation of activity does not fully account for the relationship between an individual and the environment. Therefore, the analytical framework of this study outlines and considers the key contributions made by Leontiev (1978) to activity theory in this domain.

\subsection{Activity Theory: Leontiev and Engeström}

This section will clarify two types of activity theory, namely Leontiev's (1978) and Engeström's $(1987,1999)$. Both theories focus on human cognition in context studies. Leontiev's (1978) activity theory highlights the motive, the goal and conditions of the activity within the cognition and context framework, while Engeström's $(1987,1999,2001)$ activity theory emphasizes the mediating resources and the community feature of the activity 
in its exploration of the human mind in the society. This emphasis on tools, including social media artefacts, as mediators of activity, focuses attention on the activity itself as well as the interaction between the learner-users and the social media tools. The learner-user is seen to be doing something other than using the social media tools. In this regard, the social media is the tool through which the learner-users achieve their objectives (to master the English). According to this perspective, evaluation of social media artefacts should focus not only on identifying usability issues but also on examining how well the tool supports the learner-users' informal learning activities of ESL at a residential college.

\subsection{Leontiev's Activity Theory: Motive, Goal, and Conditions}

Leontiev (1978) developed the two additional concepts of "activity" and "action" in support of Vygotsky's ideas to further explore the genesis and mediation of mind in situated contexts and proposed a formal theory of activity. Leontiev's activity theory is functionalized through three layers of analyses (Kaptelinin \& Nardi, 2006). Each layer of the structure consists of one construct (activity, action and operation) and its variable (need, motive and goal). The structure of Leontiev's activity theory is summarized in Figure 1 as follows:

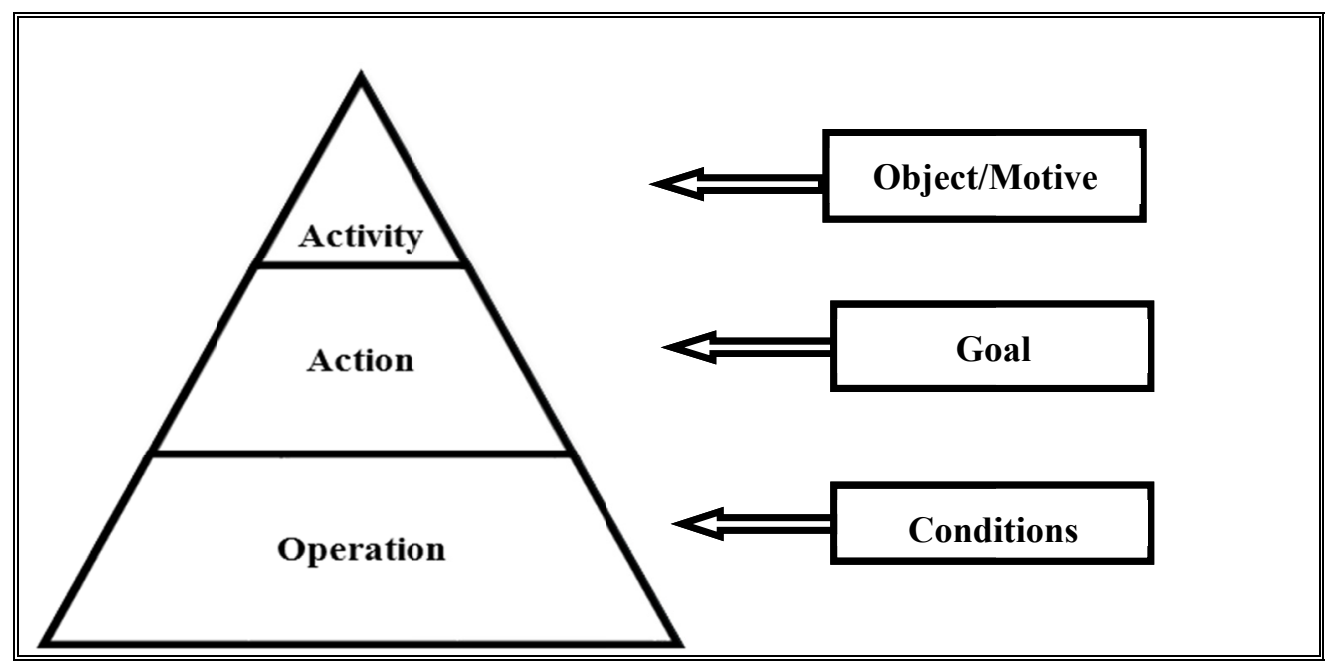

Figure 1. The hierarchical structure of Leontiev's activity theory (Leontiev, 1978, p. 62)

In Leontiev's (1978) theory, the level of activity emphasizes the reasons for the activity being performed. The activity is motivated by needs such as biological needs (for example, hunger) or culturally constructed meaningful needs when they are directed at specific objects (motives). Thus, in the current study, the activity and actions (to perceive benefits and adopt learning strategies) of social media are identified through the object-related motive, and the motive is realized in the goal-oriented action and under particular conditions. As a result, learner-users need to actively adapt their learning environment for successful informal learning construction. Therefore, this study will uncover the learners' goals and motives within social media-based informal ESL learning circumstances in order to understand the performance of a learner-user in that particular situation. The goal is determined by conditions and also influences the actions and activities (Leontiev, 1978; Kaptelinin \& Nardi, 2006). In other words, the levels of operation or routine processes that are used describe how the action is performed within the available conditions. Leontiev also highlights the holistic nature of activity systems and the continuous transformation between the three layers, namely the activity, the action and the operation. Thus, Leontiev illustrates the difference between individual and collective actions and how they relate to one another (Engeström, 2001). Moreover, the internal negotiations of such a system are the motive to force change and development of the activity.

Activity theory focuses on "human intentionality" (Kaptelinin \& Nardi, 2006, p. 10). Therefore, the tools are "for purposeful", "intentional" (p. 203) and conscious activities that contribute to learner-users' daily engagement. Kaptelinin and Nardi (2006) describe "consciousness" as "the enactment of our capacity for attention, intention, memory, learning, reasoning, speech, reflection, and imagination" (p. 8). Social media activities include operations and conscious actions where there exists intentionality influenced by the individual differences, past experiences, and the affordable conditions of the context. The main difference between operations and actions is that operations have a routine nature and require the subject's automatic attention, whereas actions involve conscious doing (Kaptelinin \& Nardi, 2006; Leontiev, 1978). Thus, actions, when they become regular ways of doing things, no longer require conscious attention and intention in their performance 
and become operations (Kaptelinin \& Nardi, 2006; Leontiev, 1978). For example, in the multi-dimensional context of this study, an advanced ESL learner may not pay attention to grammar while being engaged in Facebook conversation.

In social media activity, the unit of analysis is the whole activity of the subject, which implies the active participation of the subject. Thus, the activity is broken into the analytical components of a subject (ESL learners), tools (social media tools and ESL), object (informal ESL learning) and the affordable conditions of the context. The unit of analysis is expanded from analysing the individual as a single learner by incorporating the learner's mutual engagement in communities of practice (Lave \& Wenger, 1991; Wenger, 1998). This means including the learner's ability to act in order to fulfill learning objectives (Anderson, 2003). Therefore, the individual user has his own motives for choosing to participate or not participate in social media activities, his own motives and intentions (Kaptelinin \& Nardi, 2006; Wan, 2013). This allows an understanding of several aspects of reflective behaviour (Anderson, 2003), including choice of activities and tools, goals and continuing participation. This multi-layered analysis is helpful in understanding how activities can be illuminated into the conscious steps, automated routines of the individual and dynamic motives and object-oriented actions within the context of the activity. Therefore, some actions with social media tools may, over time, become routine processes that no longer require conscious awareness among learner-users.

In the following section, the writer draws on Engeström's activity theory as the conceptual framework underlying this study, because it points to a necessary direction for understanding the complex, evolving system of informal ESL learning mediated by social media tools. This approach provides a broad conceptual tool for thinking about the relationship between informal learning, the learners, and the resources available to the learners such as the online community and social network.

\subsection{Engeström's Activity Theory: Mediating Resources}

According to Engeström (1987), activity theory extends Vygotsky's concept of mediation by adding the construct of "community" in its triangular model to represent the structure of a collective activity system. It adds another three mediators, namely community, rules and division of labor to it. By situating mediated actions and including other people as constituents of the activity system, Engeström emphasizes the societal and collaborative nature of mediated actions and offers a greater framework (see Figure 2 below) to understand how human cognition is mediated and distributed in communities (Engeström, 1987, 1999).

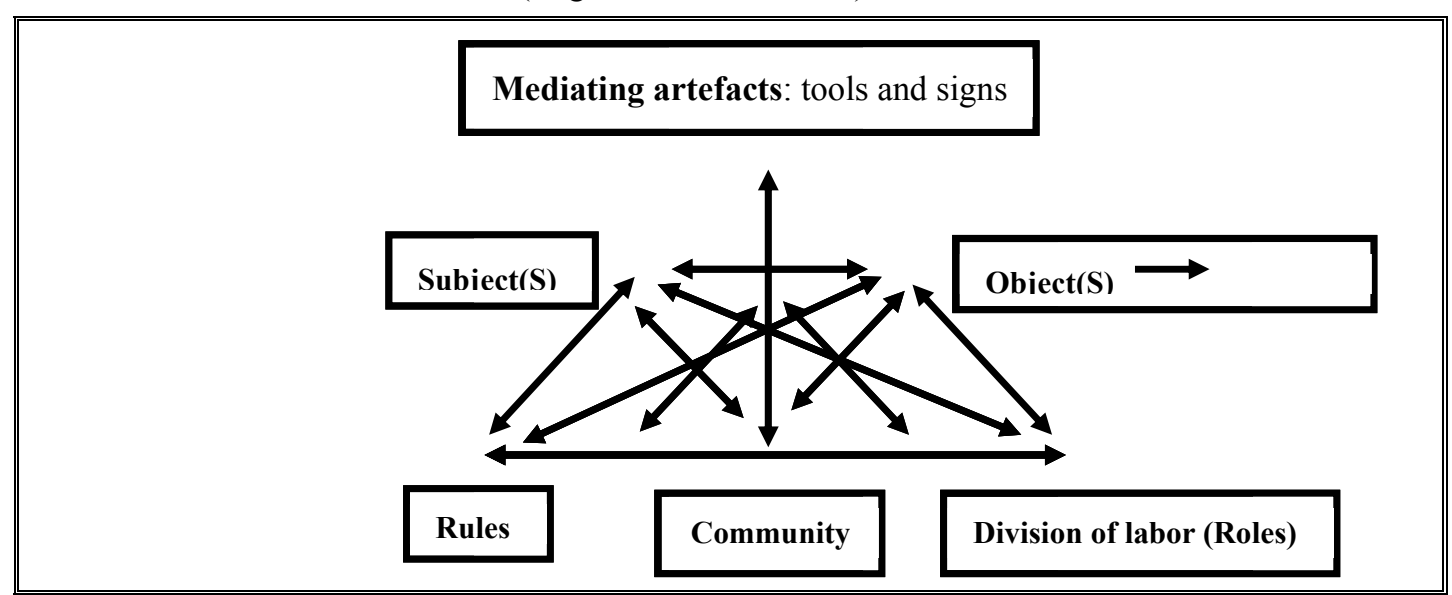

Figure 2. Activity system (based on Engeström, 1987, 1999)

As shown in Figure 2, according to activity theory, all human activity is considered to be object-oriented (Leontiev, 1978; Engeström, 1987, 1999; Kaptelinin \& Nardi, 2006) and subjects' actions towards objects in an activity system are mediated by four inter-related mediators namely mediating artefacts, rules, community and division of labor. In other words, this theory highlights the activity directed towards an objective (goal) and carried out by a community (object-orientedness). Mediating artefacts include technical artefacts (tools) and psychological artefacts (cognitive resources). In informal learning activities of ESL, technical artefacts can be computers, the Internet, social media tools such as Facebook and YouTube while psychological artefacts include language, music and multimedia materials. Engeström $(1987,1999,2001)$ also outlines the dynamic nature of the relation between the mediating artefacts which involve both external implements and internal representations. These functions and uses are in constant flux and transformation as the activity is mutually inter-related. An 
internal representation becomes externalized through speech, gesture, writing and manipulation of the material environment and vice versa, external processes become internalized. In order to understand individual learners' actions and interactions, one must know the context in which those actions are embedded, namely a clear and systematic picture of activity (Engeström, 1999).

Rules are rather loose conventions guiding the individual's actions and interactions within the system of activity. The rules or regulations in an activity system can consist of informal and implicit ways of doing things (Engeström, 1987). Community is included in an activity system to emphasize the communal nature of cognition and learning and subjects as constituents of the community. For learner-users at residential college, their social media communities are probably composed of lecturers, classmates, friends from other universities, virtual groups and family members. Division of labor is also referred to as "roles" describing the continuously negotiated distribution of powers and responsibilities among the social media participants (Wan, 2013). Learners can take on various roles such as collaborators, gamers, active and passive ESL learners. In the context of a social media activity system, community refers to the group of individual users of the social media activity system who are motivated by the same objective (learning ESL beyond the classroom) and demonstrate orientation to the same objective. As a result, the social media community shapes and directs the individual and the collective ESL activity at residential college, beyond the classroom.

It is important to note that the communication of these four mediators in informal learning activities at residential college should be perceived holistically as a collaborative knowledge construction process as each part in the activity system is in continuous interaction with the others. Activities are open systems and when a new element enters into the activity system from the outside (for example, the criticism and contradictory ideas from peers), a secondary contradiction (for example, the rules or new identity) appears between the elements. Such contradictions represent disturbances and conflicts in activity systems (Engeström, 1999, 2001). In this way, Wenger (1998) confirms that "interrelations within the community did not always arise out of mutual support and interpersonal allegiance, but sometimes through conflict, disagreement, and challenge" (Mills, 2011, p. 364). In contrast, they can create novel attempts to change activities and be used as a catalyst for growth (Engeström, 2001, p. 137). Therefore, under the direction of this theory, the article should highlight on what way artefacts and contextual components mediate interactions, and also focus on how these mediators get expanded through interactions.

Overall, Engeström's activity theory is a theory of object-driven activity and it is important to identify the various mediating resources (social media tools and language) that contribute to the production of object (ESL learning) in activity. The process of enabling conversation among social media users to trigger deep reflection on the various possibilities for social media tools integration in informal ESL learning in Malaysia constitutes the focus of this study. By this, the use of mediating resources that influence the nature of external behaviour and also the mental functioning of individual learner-users will be revealed.

\section{Conclusion}

Technological advancement has allowed the writer to recognize the value of a sociocultural framework (Vygotsky, 1978, 1986), Leontiev (1978) and Engeström (1987, 1999), for understanding and considering learning in a social world and in the cultural contexts in which events occur. In this regard, the theoretical framework developed to explain the nature of the informal English as a second language learning experienced by the Malaysian university students based on the social media technologies at residential college (outside the classroom) has provided fresh insights. This framework reveals important aspects of the dynamic and complex ways in which social media functions to either enable authentic informal language learning or limit it, depending on the users' past experiences, preferences and abilities. This application of sociocultural theory, building on the work of Vygotsky (1978, 1986), Leontiev (1978) and Engeström (1987, 1999), highlights the links between individual learner motivation and communal practices in this context.

\section{References}

Anderson, N. J. (2003). Scrolling, clicking, and reading English: Online reading strategies in a second/foreign language. The Reading Matrix, 3(3), 1-33. Retrieved from http://www.readingmatrix.com/articles/anderson/article.pdf

Engeström, Y. (1987). Learning by expanding: An activity-theoretical approach to developmental research. Helsinki: Orienta-Konsultit.

Engeström, Y. (1999). Activity theory and individual and social transformation. In Y. Engeström, R. Miettinen, \& R. Punamäki (Eds.), Perspectives on activity theory (pp. 19-38). Cambridge, New York: Cambridge 
University Press. https://doi.org/10.1017/CBO9780511812774.003

Engeström, Y. (2001). Expansive Learning at Work: Toward an activity theoretical reconceptualization. Journal of Education and Work, 14(1), 133-156. https://doi.org/10.1080/13639080020028747

Kaptelinin, V., \& Nardi, B. A. (2006). Acting with technology: Activity theory and interaction design. Cambridge, Mass: MIT Press.

Lantolf, J. P., \& Thorne, S. L. (2006). Sociocultural theory and the genesis of second language development. Oxford, New York: Oxford University Press.

Lave, J., \& Wenger, E. (1991). Situated learning: Legitimate peripheral participation. Cambridge England, New York: Cambridge University Press. https://doi.org/10.1017/CBO9780511815355

Leontiev, A. N. (1978). Activity, consciousness, and personality. Englewood Cliffs, NJ: Prentice-Hall.

Mills, N. (2011). Situated learning through social networking enterprise, mutual engagement, and a shared repertoire. CALICO Journal, 28(2), 345-368. https://doi.org/10.11139/cj.28.2.345-368

Vygotsky, L. S. (1978). Mind in society: The development of higher psychological processes. Cambridge: Harvard University Press.

Vygotsky, L. S. (1986). Thought and language. Cambridge, MA: MIT Press.

Wan, C. W. I. R. C. (2013). Perceived benefits and learning strategies of Malaysian university students in Web 2.0-based informal learning of English as a second language (Doctoral dissertation, Bendigo, Australia: La Trobe University).

Wan, C. W. I. R. C., Prain, V., \& Collet, P. (2014). Perceived Learning Strategies of Malaysian University Students in Web 2.0-based English as a Second Language Informal Learning. GEMA Online ${ }^{\circledR}$ Journal of Language Studies, 14(1), 1-12.

Wenger, E. (1998). Communities of practice: Learning, meaning, and identity. Cambridge, U.K.: Cambridge University Press. https://doi.org/10.1017/CBO9780511803932

\section{Copyrights}

Copyright for this article is retained by the author(s), with first publication rights granted to the journal.

This is an open-access article distributed under the terms and conditions of the Creative Commons Attribution license (http://creativecommons.org/licenses/by/4.0/). 